\title{
Assessment of Global Health Education: The Role of Multiple-Choice Questions
}

\section{OPEN ACCESS}

Edited by:

Shazia Qasim Jamshed, Sultan Zainal Abidin

University, Malaysia

Reviewed by:

Mary Thompson, Alson Ltd, United Kingdom Jeff Bolles,

University of North Carolina at Pembroke, United States

*Correspondence: Seema Biswas eic.bmjcases@bmj.com

Specialty section: This article was submitted to Public Health Education and Promotion,

a section of the journal Frontiers in Public Health

Received: 10 December 2020 Accepted: 11 June 2021

Published: 22 July 2021

Citation:

Douthit NT, Norcini J, Mazuz K, Alkan M, Feuerstein M-T, Clarfield AM, Dwolatzky T, Solomonov E, Waksman I and Biswas S (2021) Assessment of Global Health Education: The Role of

Multiple-Choice Questions.

Front. Public Health 9:640204.

doi: 10.3389/fpubh.2021.640204

\begin{abstract}
Nathan T. Douthit ${ }^{1,2}$, John Norcini ${ }^{3,4}$, Keren Mazuz ${ }^{5}$, Michael Alkan ${ }^{6,7,8}$, Marie-Therese Feuerstein ${ }^{6,7}$, A. Mark Clarfield ${ }^{9,10}$, Tzvi Dwolatzky ${ }^{11}$, Evgeny Solomonov ${ }^{12,13}$, Igor Waksman ${ }^{13,14}$ and Seema Biswas ${ }^{2,14 *}$
\end{abstract}

\begin{abstract}
${ }^{1}$ Department of Geriatrics, Internal Medicine Residency, East Alabama Medical Center, Opelika, AL, United States, ${ }^{2}$ BMJ Case Reports, London, United Kingdom, ${ }^{3}$ FAIMER, Educational Commission for Foreign Medical Graduates, Philadelphia, PA, United States, ${ }^{4}$ Psychiatry Department, Upstate Medical University, Syracuse, NY, United States, ${ }^{5}$ Anthropology, Hadassah Academic College, Jerusalem, Israel, ${ }^{6}$ Faculty for Health Sciences, Ben Gurion University of the Negev, Be'er Sheva, Israel, ${ }^{7}$ Medical School for International Health, BGU Faculty for Health Sciences, Be'er Sheva, Israel, ${ }^{8}$ Open Clinic, Physicians for Human Rights, Tel Aviv, Israel, ${ }^{9}$ Department of Geriatrics and Centre for Global Health, Faculty of Health Sciences, Ben Gurion University of the Negev, Be'er Sheva, Israel, ${ }^{10}$ Department of Geriatrics, McGill University, Montreal, QC, Canada, " Geriatric Unit, Rambam Health Care Campus, Faculty of Medicine, Technion-Israel Institute of Technology, Haifa, Israel, ${ }^{12}$ General and Hepatobiliary Surgery, Ziv Medical Center, Tzfat, Israel, ${ }^{13}$ The Azrieli Faculty of Medicine, Bar Ilan University, Tzfat, Israel, ${ }^{14}$ Department of Surgery, Galilee Medical Center, Nahariya, Israel
\end{abstract}

Introduction: The standardization of global health education and assessment remains a significant issue among global health educators. This paper explores the role of multiple choice questions (MCQs) in global health education: whether MCQs are appropriate in written assessment of what may be perceived to be a broad curriculum packed with fewer facts than biomedical science curricula; what form the MCQs might take; what we want to test; how to select the most appropriate question format; the challenge of quality item-writing; and, which aspects of the curriculum MCQs may be used to assess.

Materials and Methods: The Medical School for International Health $(\mathrm{MSIH})$ global health curriculum was blue-printed by content experts and course teachers. A 30-question, 1-h examination was produced after exhaustive item writing and revision by teachers of the course. Reliability, difficulty index and discrimination were calculated and examination results were analyzed using SPSS software.

Results: Twenty-nine students sat the 1-h examination. All students passed (scores above $67 \%$ - in accordance with University criteria). Twenty-three (77\%) questions were found to be easy, 4 (14\%) of moderate difficulty, and $3(9 \%)$ difficult (using examinations department difficulty index calculations). Eight questions (27\%) were considered discriminatory and 20 (67\%) were non-discriminatory according to examinations department calculations and criteria. The reliability score was 0.27 .

Discussion: Our experience shows that there may be a role for single-best-option (SBO) MCQ assessment in global health education. MCQs may be written that cover the majority of the curriculum. Aspects of the curriculum may be better addressed by non-SBO format MCQs. MCQ assessment might usefully complement other forms 
of assessment that assess skills, attitude and behavior. Preparation of effective MCQs is an exhaustive process, but high quality MCQs in global health may serve as an important driver of learning.

Keywords: global health, medical education, multiple-choice questions, assessment, single-best option

\section{INTRODUCTION}

Multiple Choice Questions (MCQs) are the most commonly used tool for assessment in medical education $(1,2)$. While other tools including short answer questions, long answer questions, oral examinations, and written reports also have an important role in assessment, the vast majority of summative examinations a medical student takes are based on MCQs $(1,3,4)$. The popularity of MCQs rests on the ease of testing a breadth of knowledge, standard setting and production of statistical data necessary for quality control of institutional question banks (4-6). Common criticisms of standard MCQs include their failure to engage higher order thinking, test attitude, behaviors or the application of clinical skills, and their failure to take into account gender and cultural biases in question response. Thus, standard MCQs are not generally associated with transformational learning $(4,5,7)$. There are, however, a multitude of MCQ styles that may, to varying degrees, test knowledge, skills, attitudes, judgement and even behavior, especially when questions are context-based.

Examples of MCQ style are given in Table 1 below which summarizes the features of each type of question: single best option (SBO); true/false statements; extended matching; situational judgement; and, script concordance questions (811). For the most part, SBO style MCQs are used to assess the biomedical curriculum. This is the case in national licensing exams such as the United States Medical Licensing Examination (12).

In comparison to the techniques used for the assessment of the basic sciences, assessment of global health learning is more problematic. While lectures and written learning resources may be rich in factual content, there is a perception among students, and perhaps even faculty, that these facts are not immediately relevant to a scientific medical curriculum, and that a grasp of global health concepts does not necessarily require a recall of facts $(13,14)$. Thus, many global health programs rely exclusively on reflective essays as assessment tools-focusing on cultural and anthropological exploration, and ethics and overseas medical experience, or on a project thesis that seeks to address a distinct research question in line with Master of Public Health programs (15-17). This is at odds with standard assessment of the biomedical curriculum which substantially requires the demonstration of recall and understanding of specific facts in order to demonstrate competence to practice.

While many medical schools describe their global health learning programs in detail, there is a paucity of research into what students actually learn on these courses. There is evidence that students know far less than they think they do (13, 14, 18, 19). Eichbaum (20) writes of a frenzied growth in global health education programs with poorly defined goals and objectives, describing the need for competencybased programs. Over the last 10 years there have been calls

TABLE 2 | Topics routinely tested by MCQ assessment and their relevance in global health.

\begin{tabular}{ll}
\hline Topic & Examples of application to Global Health \\
Definitions & Difference between people trafficking and \\
& people smuggling \\
& Difference between asylum seeker and refugee \\
International organizations & The world bank, IMF and international aid programs \\
& Millennium and sustainable development goals \\
SPHERE standards & Testing potable water \\
Biostatistics & Standards in hygiene and sanitation \\
& Diseases contributing to mortality in children under \\
the age of 5 years \\
Trauma and burns in school children \\
Infectious Disease & Parasite infestation and steps in eradication \\
Health policy & AlDS pandemic \\
Universal Health Coverage & Age-friendly cities
\end{tabular}

TABLE 1 | MCQ question types and descriptions.

\begin{tabular}{|c|c|c|c|}
\hline Question type & Components & Adjustments & Instructions \\
\hline Single best option & A question stem with multiple distractors & $\begin{array}{l}\text { Although distractors may be plausible, } \\
\text { there is a single best answer to the stem }\end{array}$ & Choose the single best answer \\
\hline True or false & A statement & Each statement is either true or false & Mark whether each statement is true or false \\
\hline Extended matching & $\begin{array}{l}\text { Stem, lead in question, options, multiple } \\
\text { distractors }\end{array}$ & $\begin{array}{l}\text { The same answer may apply to multiple } \\
\text { questions }\end{array}$ & Select one answer to each question \\
\hline Situational judgement & Scenario, variety of responses & Each response is rated by the student & Rate the appropriateness of each response \\
\hline Script concordance & $\begin{array}{l}\text { Case, relevant diagnostic/management } \\
\text { options and findings, options }\end{array}$ & $\begin{array}{l}\text { The options assess the direction and } \\
\text { intensity of new findings on the student's } \\
\text { reasoning }\end{array}$ & $\begin{array}{l}\text { Indicate whether the new finding has a positive } \\
\text { or negative effect on the hypothesis }\end{array}$ \\
\hline
\end{tabular}


TABLE 3 | Examples of global health MCQ assessment questions.

\begin{tabular}{|c|c|c|c|}
\hline Example & Question & Answers & Analysis \\
\hline $\begin{array}{l}\text { 1. Local context-linked: } \\
\text { public health program in } \\
\text { Israel }\end{array}$ & $\begin{array}{l}\text { You have been working with a team of Family } \\
\text { Medicine practitioners on a program to reduce } \\
\text { the risk of diabetes in a Bedouin community in } \\
\text { the Negev. The program aims to educate } \\
\text { families in a healthy diet and to measure blood } \\
\text { sugar and weight and encourage physical } \\
\text { exercise. After } 6 \text { months it becomes obvious } \\
\text { that the program is failing and that there is very }\end{array}$ & $\begin{array}{l}\text { A. Advising all women to cook bread with } \\
\text { brown whole meal flour } \\
\text { B. Dialogue only with Bedouin women } \\
\text { C. Failure of your team to perform blood } \\
\text { sugar and weight checks more than } \\
\text { once in } 6 \text { months } \\
\text { D. Insufficient and non-transparent funding } \\
\text { E. Too many aims to achieve in the program }\end{array}$ & $\begin{array}{l}\text { Analysis of examination results shows } \\
\text { that } 59 \% \text { selected the correct answer, } \\
31 \% \text { option B, } 7 \% \text { option A and } 1 \% \\
\text { option E (discrimination } 0.83 \text { ), none of } \\
\text { the MSIH control group selected the } \\
\text { correct answer, } 40 \% \text { selected option } \\
\text { B, } 40 \% \text { option E, } 12 \% \text { option D and } 2 \\
\text { option A (discrimination } 0 \text { ). }\end{array}$ \\
\hline
\end{tabular}

2. Global Context linked-disaster response abroad little interest from the community in engaging with the program. Which ONE of the following factors is most likely to be the reason for failure of the program?

In the aftermath of a disaster in an agricultural village, SPHERE standards are to supply a minimum of 15 liters of water per person per day as part of the disaster response. According to SPHERE standards which ONE of the following is the most urgent initial priority in water supply?
A. Advising all women to cook bread with brown whole meal flour B. Dialogue only with Bedouin women C. Failure of your team to perform blood sugar and weight checks more than D. Insufficient and non-transparent funding . Too many aims to achieve in the program option A (discrimination 0).

\author{
A. Ensuring that drinking water is free of \\ coliforms \\ B. Producing sufficient water sources in \\ order to avoid queuing for longer than $1 \mathrm{~h}$ \\ C. Providing sufficient water for essential \\ livestock \\ D. Reducing the environmental impact of \\ the water sources identified and used \\ E. Reducing the distance of all households \\ to the nearest water point to $5 \mathrm{~m}$
}

Analysis of examination results shows that all of the study group answered this question correctly (discrimination 0), $64 \%$ of the MSIH control group answered correctly, $16 \%$ selected option C, $12 \%$ option B, $4 \%$ option D and $4 \%$ option D

(discrimination-0.12) for an agreement on undergraduate global health education frameworks and competencies (21-28). These competencies are similar to those developed by the Joint US/Canadian Committee on Global Health Core Competencies and those discussed in the 2008 Bellagio conference on global health education and include learning about: the global burden of disease; health implications of travel, migration and displacement; social and economic determinants of health; population resources and environment; globalization of health and health care; health care in low-resource settings; and, human rights in global health. The global health competencies of the Medical School for International Health (MSIH), Ben-Gurion University in Be'er Sheva, Israel, mirror these international standards.

Reflective essays alone cannot test the breadth of such curricula and do not reflect the broad range of global health competencies. Moreover, this style of assessment encourages students to view global health as a "soft" science, less of a priority in learning than the traditional disciplines usually covered in the biomedical curriculum, and to overestimate how much they actually know about global health $(13,14,29)$.

Table 2 gives examples of factual learning outcomes in the global health curriculum. Just as the breadth of the biomedical curriculum may be assessed through a SBO MCQ, we propose that for substantial areas of the global health curriculum SBO MCQs may be a useful assessment tool. Table 3 gives examples of how these learning outcomes might be assessed using different MCQ formats.

In this research we describe the challenges and limitations of devising MCQs for the assessment of knowledge across the global health curriculum and report our experience of SBOs.

\section{MATERIALS AND METHODS}

\section{Context}

The Medical School for International Health (MSIH) was founded in 1996 as a collaborative effort between the Ben-Gurion University of the Negev in Be'er Sheva, Israel, and the Columbia University Medical Center in New York. The goal of the medical school is to produce physicians who are competent international health practitioners $(30,31)$. Students are mainly from the USA, some are from Canada and a few from outside North America. Teaching and assessment are conducted in English.

As part of a first year global health teaching program review at MSIH we sought to assess global health learning: looking specifically to see how many of the curricular learning outcomes may be taught and learned over a two-semester global health course; and how to assess what has been learned. Changes to the course and assessment were gradual-over, at least, 14 months (spanning two taught courses). The number of guest lectures was reduced from previous iterations of the course and student involvement in local community programs and patient interaction increased on practical placements. Material from practical placements was incorporated into lectures so that, in principle, all students had exposure to the same learning objectives within the curriculum. Learning objectives from published global health competencies were mapped to the teaching curriculum. MCQs were chosen as they were already in widespread use across the biomedical curriculum. A 30question SBO MCQ examination was designed and administered to students at the end of the course.

\section{Blue Printing the Curriculum}

Learning objectives within each section of the global health curriculum were defined and teaching faculty agreed on 
TABLE 4 | MCQ Blueprint for global health learning objectives.

\begin{tabular}{ll}
\hline GH Organizations (5\%) & Number o \\
& Questions
\end{tabular}

History $\quad 0-1$

Current role

\section{Health Systems 5\%}

Structures of healthcare systems

Application of health services management to lower and middle income countries

Concept and dimensions of health system performance

National, inter-organizational, community and patient level interventions to improve health systems

\section{Health Economics 4\%}

Major financing methods for health care and global health efforts

Key factors in choosing the type of health care financing system

Major sources of funding in global health and how resources are allotted

\section{Health Policy 5\%}

How health policies are made and implemented

How data on global health measures affect policy change and development

\section{Politics 1\%}

Importance of local and international politics in the delivery and efficacy of global health and medicine

Different methods and tools that healthcare providers can utilize for political advocacy

\section{Global Burden of Disease}

\section{Determinants of Health $10 \%$}

Why it is important to measure health and disease

Composite measures of burden of disease, their relative strengths and weaknesses, and how they are used in public health literature, World Health Organization reports

Understanding of poverty and global health inequalities

\section{Global Patterns of Morbidity and Mortality $\mathbf{3} \%$}

Measures of morbidity and mortality used globally

Interpretation of tests and how they apply to global health

Epidemiology, Biostatistics and Surveillance 2\%

Measures of morbidity and mortality used globally

Interpretation of tests and how they apply to global health

\section{Infectious and Chronic Disease 5\%}

Epidemiology of various diseases and the threat they pose to health around the world

Leading causes of morbidity and mortality around the world in low, middle and high income countries

Describe nutrition problems around the world

Describe key interventions for malnutrition settings

Understand the global impact of injuries

Understand trends and changes in chronic disease incidence

Identify reasons for changes in chronic disease incidence and prevalence

Know the range of prevention and treatment strategies for chronic diseases in a range of international settings

$0-1$
TABLE 4 | Continued

\section{Global Burden of Disease}

Number of

Questions

\section{Environmental Health 5\%}

Understand how geography and climate of a region can impact

human health

Understand the importance of environmental issues such as pollution, natural disasters and climate change and the impact they have on health

\section{Cross Cultural Medicine}

Number of Questions

\section{Cultural Sensitivity $1 \%$}

1-2 Role that culture plays in the practice of medicine and global health

Culturally distinct beliefs, attitudes and practices relating to health

\section{and medicine}

\section{Medical Anthropology 4\%}

Practice and theory of medical anthropology and its role in global health and medicine

Vulnerable Populations

\section{1-2 Maternal and Child Health $\mathbf{4} \%$}

Social and economic context of maternal and child health

Basic terms and definitions of indicators specific to these populations

Main causes of morbidity and mortality for mothers, neonates,

$1-2$ infants, and children

Maternal health issues and interventions as distinct from other women's health issues

Low-cost, effective, community-based approaches to intervention

Principles and laws governing international humanitarian assistance

Basic needs for human survival including water, food, sanitation and safety

Most common causes of morbidity and mortality in populations affected by conflict, disaster

Key assessment strategies and public health interventions in disaster management

0-1 Human rights legislation and enforcement

0-1 $\quad$ Aging Populations 4\%

Demography of global aging and its relationship to non-communicable diseases

How the expanding elderly population will influence global health

\section{1-2 in the future}

\section{Mental Health 4\%}

Epidemiology and impact of mental health issues on populations

\section{Poverty $4 \%$}


TABLE 4 | Continued

Vulnerable Populations
How both absolute and relative poverty act as key determinants of
health

\section{Primary Care Medicine \\ Primary Care Medicine}

Number of Questions

$1-2$

Number of Questions

\section{Primary care in global health $\mathbf{4} \%$}

Define primary care and understand the way it is defined and practiced in different cultures and health systems

Understand the history of primary care and its global importance today

Recognize how countries with inadequate primary healthcare are adversely affected and how stressors are manifest on primary healthcare providers

Identify the various ways in which access to primary care can be blocked or facilitated

\section{Preventative Medicine 4\%}

Identify strategies and goals of health systems to prevent illness, including education, screening, vaccination and prophylaxis

Be familiar with current trends in national and international

prevention programs for infectious and chronic illness.

\section{Global Pediatrics 4\%}

Understand the unique health needs of infants, children and adolescents

Be familiar with organizations and programs geared toward child health

Be familiar with global pediatric vaccination recommendations

\section{Sexual and Reproductive Health $\mathbf{4} \%$}

Understand the unique health needs of infants, children and adolescents

Be familiar with organizations and programs geared toward child health

Be familiar with global pediatric vaccination recommendations

\section{Access to Essential Medicines 4\%}

Understand the current definition and suggested list of essential medications as defined by the WHO and Doctors Without Borders

Be familiar with current efforts and limitations to increase global access to essential medications

\section{Global Health Ethics}

\section{Global Health Equity $2 \%$}

Describe the meaning of the right to health and understand the concept of social justice

Describe the difference between equity and equality

Describe the major factors in global health disparities

\section{Equity in knowledge sharing $\mathbf{2 \%}$}

Understand the ethical reasoning for open source resources

Understand the concept and rationale for open-source journals

Understand the technical aspects of open-access technology including mobile data collection and medical records

the weighting of topics within the curriculum in terms of MCQ assessment (Table 4). Teachers prepared learning materials (lectures and discussion topics) with these
TABLE 5 | Statistics of administered global health examinations.

Examination statistics from 30-question MCQ paper

Average

Median

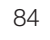

Standard Deviation

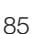

Reliability

6.3

0.27

Number of questions

30

Number of students

Students passing (>65)

29

29

Excellent scores (>90)

0

Failed $(<65)$

Minimum-maximum score

0

Difficulty of Questions

Easy (90-100)

70-97

Easy (80-89)

$20(67 \%)$

Easy (70-79)

$2(7 \%)$

$1(3 \%)$

Moderate (60-69)

$3(10 \%)$

Moderate (50-59)

1 (3\%)

Difficult (40-49)

Difficult (30-39)

$1(3 \%)$

$1(3 \%)$

$1(3 \%)$

Distribution of Discrimination

High (>0.35)

$3(10 \%)$

$2(7 \%)$

$3(10 \%)$

$20(67 \%)$

$2(7 \%)$

learning objectives in mind and prepared MCQs based on these objectives.

\section{Item Writing and Testing}

MCQs were written by all (four) teachers of the course who taught distinct parts of the curriculum. The SBO format was chosen over the other MCQ styles as there was only one correct answer per question, there was broader agreement on a single correct answer, and questions were deemed less susceptible to guessing. Each question focused on a single learning objective. The final 30 questions chosen out of 100 authored by all teachers of the course were agreed to represent a broad representation of the course material.

The 30 questions were chosen after exhaustive item review. Items were discussed and tested with the faculty (seven teachers from MSIH and four teachers from other faculties), independently (forty medical students in the United Kingdom and seven students in Israel at a different medical school). Criteria for agreement on the final 30 questions comprising the examination were that each question had a meaningful stem free of irrelevant detail, the stem ended with a question, negative phrasing was not used, and that distractors were clear, concise, roughly the same number of words, mutually exclusive and independent of each other. Distractors included common 
misconceptions discussed in class and were plausible alternatives unless students' precise knowledge of the topics was tested. Any questions with "all/none of the above" or non-heterogeneous distractors were omitted or rewritten. Distractors were listed in alphabetical order.

\section{Data Analysis}

Item analysis and exam statistics provided information about the quality of MCQs and difficulty and discrimination index. The aim was to develop questions that would principally test the recall of facts (in particular definitions, criteria and structural frameworks used in global health as in Table 2).

Reliability was based on Kuder-Richardson 21 (testing reliability of binary variables-where an answer is right or wrong when questions do not vary widely in their level of difficulty). We assumed all questions were equal in difficulty and the binary variable was a correct or incorrect answer. Difficulty-index was calculated as follows:

Difficulty Index $=\frac{\text { Number of students who answered correctly }}{\text { Number of students who answered }} \times 100$

Discrimination was computed by comparing students with the highest score to students with the lowest score.
Our experience indicates that identifying 'factual' aspects of the global health curriculum is possible and that SBO MCQs may be tailored to assess recall and application of these facts. As factual aspects are spread across the curriculum (Table 4), global health MCQs may be employed to assess learning of the breadth of the curriculum just as in the basic sciences. Particular "facts" include definitions, roles of organizations, epidemiological trends in disease prevalence and agreed global standards or healthrelated goals (Table 2 ).

We believe that introducing MCQ assessment into a global health curriculum may introduce students to the perception of global health learning as a "hard" science with knowledge and skill competencies in common with the rest of the standard biomedical curriculum. Further, we believe that self-assessment using MCQs may assist students in defining their own learning needs and identify deficiencies in knowledge and competency for practice.

In combination with other assessment modalities based on patient-focused assessment tools such as the global health case report, the MCQ may have a role to play in global health education (33-35). Indeed, MCQs may focus learning in what some students may perceive a rather nebulous and unfocused subject. According to Bloom's taxonomy (Figure 1) MCQ-based assessment may overly emphasize the bottom two phases, "remember," and "understand," while neglecting

$$
\text { Discrimination }=2 \times\left(\frac{\text { Number of students in highest group with correct answer }- \text { number of students in lowestgroup with correct answer }}{\text { Total number of students in both groups }}\right)
$$

\section{RESULTS}

Examples of multiple-choice questions used in the 30-question examination are seen in Table 3. The MSIH Examinations Department administered and analyzed student performance in the examination using their standard statistical tools and WHO guidelines. One-way ANOVA was applied to detect differences between the student scores using Statistical Product and Service Solutions (SPSS) software. This software was also used to determine discrimination, difficulty and reliability.

Table 5 shows the examination statistics for the 30-question examination. Twenty-nine students sat the 1-h examination. All students passed (scores above $67 \%$ as determined by MSIH examinations criteria). Twenty-three (77\%) questions were found to be easy, 4 (14\%) of moderate difficulty, and 3 (9\%) difficult according to the examinations office statistical criteria. Eight questions (27\%) were considered discriminatory and $20(67 \%)$ were non-discriminatory. The reliability score was 0.27 .

\section{DISCUSSION}

\section{The Role of MCQ in Global Health Assessment}

The function of assessment has been described as maximizing student competence while guiding subsequent learning. Multiple assessment methods are needed to test all aspects of competence (32). Assessment (or practice for assessment) drives learning. higher orders of learning. Topic selection and item writing, therefore, require careful thought that encourages critical (and reflective) thinking, where possible-using diverse MCQ formats (Table 3) (4, 37-39).

\section{Topics Suitable for MCQ}

The suitability of SBO MCQs in assessing breadth of knowledge is relevant in global health assessment $(4,40)$. Few medical fields require as broad a knowledge base as global health. Topics suitable for MCQ assessment must be identified with clear learning and assessment objectives in mind. The process of defining learning objectives, blueprinting, developing the practical course and putting together a final examination to review took 14 months. We were at pains to ensure that we had taught what we planned to assess and assessed what we knew we had taught. Particular emphasis was placed on understanding why distinct definitions exist to describe vulnerable populations and the rights and entitlements these entail, for example (Table 2). While students may feel that they have a grasp of these topics, choosing only one option from a list of distractors forces the student to accept that precise knowledge and understanding of the topics is required to practice safely and access the care their patients require. Table 6 offers an example of a question that we believe tests the application of knowledge and understanding of the social determinants of health. 


\section{Bloom's Taxonomy}

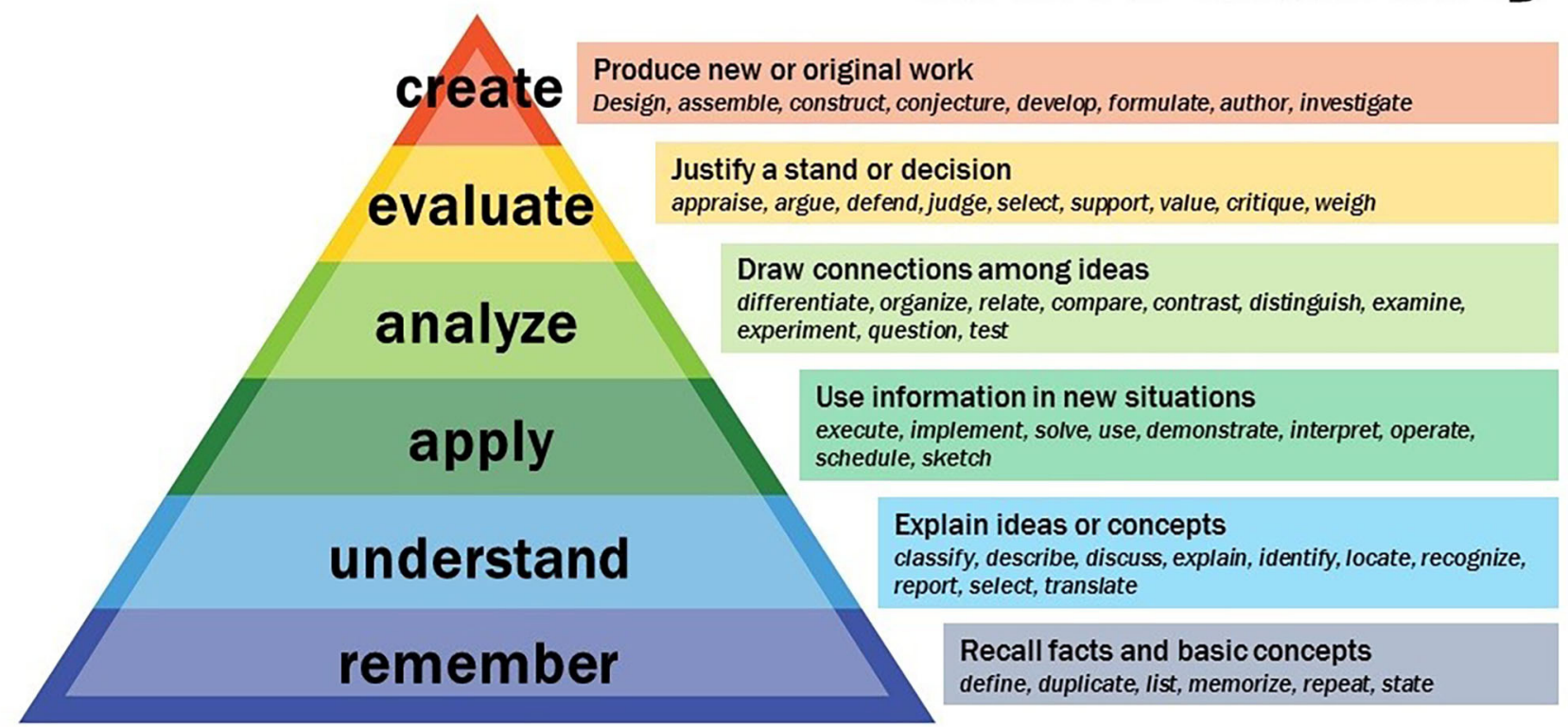

(c) (1) Vanderbilt University Center for Teaching

FIGURE 1 | Bloom's taxonomy [Creative Commons, Vanderbilt University. Bloom's Taxonomy. (internet) Vanderbilt University (36). Obtained from https://cft.vanderbilt. edu/guides-sub-pages/blooms-taxonomy/ on 1/3/2020].

\section{Item Writing and Quality Control}

Writing "good" global health questions is a challenge that requires multiple contributors of questions, exhaustive criticism and review. MCQs should be based on a blueprint of the curriculum and test topics most suited to MCQstyle assessment. We emphasized context as students were encouraged to learn global health on practical placements as well as lectures (41). Our aim is to better engage students (providing real-life experience of global health problems patients experience) and make assessment relevant to future clinical practice. Epstein (6) explains that "questions with rich descriptions of the clinical context invite the more complex cognitive processes that are characteristic of clinical practice. Conversely, context-poor questions can test basic factual knowledge but not its transferability to real clinical problems." Thus, we believe that context-based questions may place potentially abstract global health concepts in practical, realistic settings relevant to students, easier to identify, recall, and apply knowledge.

Although reliability may have been improved by increasing the number of test items in the exam, we opted for a 30question examination so that the assessment would be completed within $1 \mathrm{~h}$. We selected 30 questions that represented the breadth of the curriculum and our blueprint. A greater spread of scores with more moderately difficult questions (Difficulty Index $0.4-0.8$ ) and discriminatory questions, would also have been preferable.
TABLE 6 | MCQ example testing understanding and application.

Israel' National Health Insurance Law came into effect in 1995. This entitles refugees, migrants and asylum seekers to emergency health care. The influence of this legislation on public health is an example of a/an impacting a of health inequality.

A. Downstream social determinant of health; structural determinant

B. Downstream social determinant of health; intermediary determinant

C. Upstream social determinant of health; structural determinant

D. Upstream social determinant of health; intermediary determinant

E. Upstream social determinant of health; exceptional determinant

\section{Limitations}

The most obvious deficiency in this research is that the examination was run only once, and exam questions subjected to statistical analysis only once. This substantially limits any conclusion regarding reliability and validity. Clearly testing needs to be repeated. The research period (a 3-year $\mathrm{PhD}$ program that included the running of the global health course) precluded repeated testing. Also important is the development of other styles of MCQs to evaluate their role in the assessment of attitudes and behaviors expected of global health practitioners. We have since increased our bank of questions and written MCQs in other formats better suited to testing judgement, decision making and situational awareness. Examples are given in Table 7. Further 
TABLE 7 | Global health examination questions in distinct MCQ formats.

\begin{tabular}{|c|c|c|c|c|c|c|c|c|}
\hline Single Best Option & \multicolumn{8}{|c|}{$\begin{array}{l}\text { Implementing your programme of multi-drug resistant tuberculosis treatment in the city, an indepe } \\
\text { years of your programme there is no obvious change in prevalence of the disease. This is difficult } \\
\text { medication for free and health-workers reach out to the population via house calls and visits to pla } \\
\text { well-accepted programme. } \\
\text { Which ONE of the following is the most likely explanation for a lack of impact of the programme? } \\
\text { A. Employers are unwilling to participate in programmes where staff may need to be isolated } \\
\text { B. Schools are unwilling to participate in programmes where children may require medication } \\
\text { C. Stigma prevents patients in need of treatment coming forward } \\
\text { D. There is no outreach programme for the homeless } \\
\text { E. The number of households in the city has doubled in the last year }\end{array}$} \\
\hline True or False & \multicolumn{8}{|c|}{$\begin{array}{l}\text { Which of the following statements is true of the fundamental aims of Universal Health Coverage? } \\
\text { A. Accountability in health care spending } \\
\text { B. Commitment to a national health budget in line with local health costs } \\
\text { C. Free healthcare for the most vulnerable } \\
\text { D. Health care delivery prioritized according to population need } \\
\text { E. Setting minimum standards in health care for all }\end{array}$} \\
\hline Extended Matching & \multicolumn{8}{|c|}{$\begin{array}{l}\text { Theme: } \\
\text { A. Social accountability } \\
\text { B. Social capital } \\
\text { C. Social inclusion } \\
\text { D. Social justice } \\
\text { E. Social welfare } \\
\text { For each situation below select the most appropriate social construct } \\
\text { Question } 1 \\
\text { Small holding farmers in } 5 \text { neighboring villages form a co-operative to set pricing on sales to local markets B } \\
\text { Question } 2 \\
\quad \text { Medical schools revise their curricula to include their commitment to local community needs A }\end{array}$} \\
\hline Situational Judgement & \multicolumn{8}{|c|}{$\begin{array}{l}\text { You accompany the parents to an outpatient appointment for their } 7 \text {-year-old child with cystic fibrosis. You know the family well and have been } \\
\text { following up the child in the community with home visits as part of your global health course. You get along well with the child and his parents. } \\
\text { The doctor asks whether the child has been eating in accordance with the dietary advice given to the parents several months ago. You know } \\
\text { that mealtimes are a challenge and most of the time, the only food the child will eat is a small piece of pizza. The parents nod strongly in } \\
\text { agreement that they have been sticking to the diet and the doctor adds that she can see that the child looks well although he is below the } 75 \text { th } \\
\text { percentile in weight. } \\
\text { Please rank your potential actions in order or appropriateness with } 1 \text { being the most appropriate and } 4 \text { being the least appropriate. } \\
\text { A. You keep quiet during the consultation as the child seems to be well regardless of any particular diet } \\
\text { B. You keep quiet but raise the issue politely with the family once you have left the consultation room } \\
\text { C. You politely joke during the consultation that mealtimes are such a challenge, most of the time the pizza is the only food the child will eat } \\
\text { D. You arrange to meet the doctor later to express your concerns about the child's diet }\end{array}$} \\
\hline \multirow[t]{7}{*}{ Script Concordance } & \multicolumn{8}{|c|}{$\begin{array}{l}\text { You have been working with people living in a village near a river who have reported becoming ill after drinking water believed to be } \\
\text { contaminated by a leak of detergent reported by a nearby detergent factory } 4 \text { weeks earlier. The leak was repaired within } 24 \mathrm{~h} \text { of discovery by } \\
\text { the factory owners. }\end{array}$} \\
\hline & & If you were thinking that & And you find that & & $\mathbf{s} \mathrm{Hy}_{\mathbf{s}}$ & & m & \\
\hline & A. & $\begin{array}{l}\text { Detergent leaked into the river from the } \\
\text { factory }\end{array}$ & The factory is downstream of the village & -2 & -1 & 0 & +1 & +2 \\
\hline & B. & $\begin{array}{l}\text { Drinking water in the village should be } \\
\text { filtered }\end{array}$ & $\begin{array}{l}\text { There are no microorganisms in the } \\
\text { community water tank of the village }\end{array}$ & -2 & -1 & 0 & +1 & +2 \\
\hline & C. & $\begin{array}{l}\text { The leak has caused detergent to } \\
\text { contaminate the river }\end{array}$ & $\begin{array}{l}\text { Fish in the river near the factory were found } \\
\text { dead } 4 \text { weeks ago }\end{array}$ & -2 & -1 & 0 & +1 & +2 \\
\hline & D. & River water is contaminated by dead fish & $\begin{array}{l}\text { There are no reports of illness in villages } \\
\text { upstream of the river in the last } 4 \text { weeks }\end{array}$ & -2 & -1 & 0 & +1 & +2 \\
\hline & E. & $\begin{array}{l}\text { Detergent is present in harmful } \\
\text { concentrations in the river } 4 \text { weeks after } \\
\text { the leak was repaired }\end{array}$ & $\begin{array}{l}\text { Samples of river water tested } 3 \text { weeks ago } \\
\text { after the leak was repaired were taken from } \\
\text { shallow water near the river bank }\end{array}$ & -2 & -1 & 0 & +1 & +2 \\
\hline
\end{tabular}

testing and analysis of all formats of MCQs for global health teaching and learning is planned.

\section{Conclusion}

Global health curricula now have internationally agreed defined competencies and learning objectives (42). As medical teaching worldwide becomes increasingly standardized, there is a need to define precise measures of assessment of student learning that may be used in combination with existing assessment tools such as reflective essays or case reports. We propose further development of MCQs in their diverse formats and testing so that we may determine, not simply their utility in testing what 
has been learned, but how this knowledge may be applied in the practice of doctors who study global health.

\section{DATA AVAILABILITY STATEMENT}

The raw data supporting the conclusions of this article will be made available by the authors without undue reservation.

\section{ETHICS STATEMENT}

The studies involving human participants were reviewed and approved by Ben Gurion University IRB. The patients/participants provided their written informed consent to participate in this study.

\section{AUTHOR CONTRIBUTIONS}

$\mathrm{SB}$ designed and researched the material. SB and ND wrote the article. SB, KM, MA, and M-TF wrote the questions.

\section{REFERENCES}

1. Grainger R, Dai W, Osborne E, Kenwright D. Medical students create multiple-choice questions for learning in pathology education: a pilot study. BMC Med Educ. (2018) 18:1-8. doi: 10.1186/s12909-018-1312-1

2. Kilgour JM, Tayyaba S. An investigation into the optimal number of distractors in single-best answer exams. Adv Health Sci Educ. (2016) 21:57185. doi: 10.1007/s10459-015-9652-7

3. Mehta B, Bhandari B, Sharma P, Kaur R. Short answer open-ended versus multiple-choice questions: a comparison of objectivity. Ann Natl Acad Med Sci. (2016) 52:173-82. doi: 10.1055/s-0040-1712619

4. Javaeed A. Assessment of higher ordered thinking in medical education: multiple choice questions and modified essay questions. MedEdPublish. (2018). 7. doi: 10.15694/mep.2018.0000128.1

5. Farooqui F, Saeed N, Aaraj S, Sami MA, Amir M. A comparison between written assessment methods: multiple-choice and short answer questions in end-of-clerkship examinations for final year medical students. Cureus. (2018) 10:e3773. doi: 10.7759/cureus.3773

6. Epstein RM. Assessment in medical education. N Engl J Med. (2007) 356:38796. doi: 10.1056/NEJMra054784

7. Palmer EJ, Devitt PG. Assessment of higher order cognitive skills in undergraduate education: modified essay or multiple choice questions? Research paper. BMC Med Educ. (2007) 7:1-7. doi: 10.1186/1472-6920-7-49

8. Fournier JP, Demeester A, Charlin B. Script concordance tests: guidelines for construction. BMC Med Inform Decis Mak. (2008) 8:1-7. doi: 10.1186/1472-6947-8-18

9. Patterson F, Zibarras L, Ashworth V. Situational judgement tests in medical education and training: research, theory and practice: AMEE Guide No. 100. Med. Teacher. (2016) 38:3-17. doi: 10.3109/0142159X.2015.1072619

10. Schuwirth LW, van der Vleuten CP. Written assessment. Br Med J. (2003) 22:643-5. doi: 10.1136/bmj.326.7390.643

11. van Bruggen L, Manrique-van Woudenbergh M, Spierenburg E, Vos J. Preferred question types for computer-based assessment of clinical reasoning: a literature study. Pers. Med. Educ. (2012) 1, 162-171. doi: 10.1007/s40037-012-0024-1

12. Federation of State Medical Boards (FSMB) and National Board of Medical Examiners (NBME). Step 1: Question Formats. (2020). Available online at: https://www.usmle.org/step-1/\#question-formats (accessed on February 1, 2020).

13. Bozorgmehr K, Menzel-Severing J, Schubert K, Tinnemann P. Global Health Education: a cross-sectional study among German medical students to identify needs, deficits and potential benefits (Part 2 of
JN, AC, TD, ES, and IW evaluated the questions. All coauthors were involved in revising the article for important intellectual content and gave final approval of the version to be published.

\section{FUNDING}

This work was supported in part by funding from Ben-Gurion University of the Negev for SB's PhD thesis work.

\section{ACKNOWLEDGMENTS}

The authors would like to thank the students, faculty and colleagues who participated in the item-writing and testing process, the MSIH examinations department, and the students who participated in this course and sat the examination.
2: Knowledge gaps and potential benefits). BMC Med Educ. (2010) 10:1-19. doi: 10.1186/1472-6920-10-67

14. Bozorgmehr K, Schubert K, Menzel-Severing J, Tinnemann P. Global Health Education: a cross-sectional study among German medical students to identify needs, deficits and potential benefits (Part 1 of 2: mobility patterns andamp; educational needs and demands). BMC Med Educ. (2010) 10:66. doi: 10.1186/1472-6920-10-66

15. Aulakh A, Tweed S, Moore J, Graham W. Integrating global health with medical education. Clin Teach. (2017) 14:119-23. doi: 10.1111/tct.12476

16. Moran D, Edwardson J, Cuneo CN, Tackett S, Aluri J, Kironji A, et al. Development of global health education at Johns Hopkins University School of Medicine: a student-driven initiative. Med Educ Online. (2015) 20:28632. doi: 10.3402/meo.v20.28632

17. Rowson M, Smith A, Hughes R, Johnson O, Maini A, Martin S, et al. The evolution of global health teaching in undergraduate medical curricula. Global Health. (2012) 8:1-8. doi: 10.1186/1744-8603-8-35

18. Rosling H. The joy of facts and figures. Bull World Health Organ. (2013) 91:904-5. doi: 10.2471/BLT.13.031213

19. Schell CO, Reilly M, Rosling H, Peterson S, Mia Ekström A. Socioeconomic determinants of infant mortality: a worldwide study of 152 low-, middle, and high-income countries. Scand J Public Health. (2007) 35:28897. doi: $10.1080 / 14034940600979171$

20. Eichbaum Q. The problem with competencies in global health education. Acad Med. (2015) 90:414-7. doi: 10.1097/ACM.0000000000000665

21. Ablah E, Biberman DA, Weist EM, Buekens P, Bentley ME, Burke $\mathrm{D}$, et al. Improving global health education: development of a global health competency model. Am J Trop Med Hyg. (2014) 90:560-5. doi: 10.4269/ajtmh.13-0537

22. Arthur MA, Battat R, Brewer TF. Teaching the basics: core competencies in global health. Infect Dis Clin North Am. (2011) 25:347. doi: 10.1016/j.idc.2011.02.013

23. Battat R, Seidman G, Chadi N, Chanda MY, Nehme J, Hulme J, et al. Global health competencies and approaches in medical education: a literature review. BMC Med Educ. (2010) 10:1-7. doi: 10.1186/1472-6920-10-94

24. Cole DC, Davison C, Hanson L, Jackson SF, Page A, Lencucha R, et al. Being global in public health practice and research: complementary competencies are needed. Can J Public Health. (2011) 102:394-7. doi: 10.1007/BF03404183

25. Harmer A, Lee K, Petty N. Global health education in the United Kingdom: a review of University undergraduate and postgraduate programmes and courses. Public Health. (2015) 129:797-809. doi: 10.1016/j.puhe.2014.12.015

26. Jogerst K, Callender B, Adams V, Evert J, Fields E, Hall T, et al. Identifying interprofessional global health competencies 
for 21st-century health professionals. Ann Global Health. (2015) 81:239-47. doi: 10.1016/j.aogh.2015.03.006

27. Margolis CZ. Carmi Z Margolis on Global Health Education. (2009). Available online at: http://www.rockefellerfoundation.org/bellagio-center/ conferencesand-residencies/17709 (accessed on February 1, 2020).

28. Peluso MJ, Encandela J, Hafler JP, Margolis CZ. Guiding principles for the development of global health education curricula in undergraduate medical education. Med Teach. (2012) 34:653-8. doi: 10.3109/0142159X.2012.687848

29. Blum N, Berlin A, Isaacs A, Burch WJ, Willott C. Medical students as global citizens: a qualitative study of medical students' views on global health teaching within the undergraduate medical curriculum. BMC Med Educ. (2019) 19:1-9. doi: 10.1186/s12909-019-1631-x

30. Margolis CZ, Deckelbaum RJ, Henkin Y, Baram S, Cooper P, Alkan ML. A medical school for international health run by international partners. Acad Med. (2004) 79:744-51. doi: 10.1097/00001888-200408000-00005

31. Willott C, Khair E, Worthington R, Daniels K, Clarfield, AM. Structured medical electives: a concept whose time has come? Glob Health. (2019) 15, 1-7. doi: 10.1186/s12992-019-0526-2

32. Moghaddam AK, Khankeh HR, Shariati M, Norcini J, Jalili M. Educational impact of assessment on medical students' learning at Tehran University of Medical Sciences: a qualitative study. BMJ Open. (2019) 9:e031014. doi: 10.1136/bmjopen-2019-031014

33. BMJ. Global Health. BMJ Case Reports. (2020). Available online at: https:// casereports.bmj.com/pages/global-health/ (accessed on February 3, 2020).

34. Biswas S. Writing a global health case report. Student BMJ. (2015). 23:h6108. doi: 10.1136/sbmj.h6108

35. Douthit NT, Biswas S. Global health education and advocacy: using BMJ case reports to tackle the social determinants of health. Front Publ Health. (2018) 6:114. doi: 10.3389/fpubh.2018.00114

36. Vanderbilt University. Bloom's Taxonomy. (2020). Available online at: https:// cft.vanderbilt.edu/guides-sub-pages/blooms-taxonomy/ (accessed March 1, 2020).
37. Kerry VB, Ndung'u T, Walensky RP, Lee PT, Kayanja VFI, Bangsberg, DR. Managing the demand for global health education. PLoS Med. (2011) 8:e1001118. doi: 10.1371/journal.pmed.1001118

38. Leinster S. Evaluation and assessment of social accountability in medical schools. Med Teach. (2011) 33:673-6. doi: 10.3109/0142159X.2011.590253

39. Wilkie RM, Harley C, Morrison C. High level multiple choice questions in advanced psychology modules. Psychol Learn Teaching. (2009) 8:306. doi: 10.2304/plat.2009.8.2.30

40. Elstein AS. Beyond multiple-choice questions and essays: the need for a new way to assess clinical competence. Acad Med. (1993) 68:2449. doi: 10.1097/00001888-199304000-00002

41. Biswas S, Douthit NT, Mazuz K, Morrison Z, Patchell D, Ochion M, et al. Implementing a practical global health curriculum: the benefits and challenges of patient-based learning in the community. Front Public Health. (2020) 8:283. doi: 10.3389/fpubh.2020.00283

42. Global health Essential Core Competencies (GHEC). AFMC Resource Group/GHEC Committee (2008), 1-8.

Conflict of Interest: SB is editor-in-chief of BMJ Case Reports which publishes Global Health case reports. ND is an associate editor of BMJ Case Reports.

The remaining authors declare that the research was conducted in the absence of any commercial or financial relationships that could be construed as a potential conflict of interest.

Copyright (C) 2021 Douthit, Norcini, Mazuz, Alkan, Feuerstein, Clarfield, Dwolatzky, Solomonov, Waksman and Biswas. This is an open-access article distributed under the terms of the Creative Commons Attribution License (CC BY). The use, distribution or reproduction in other forums is permitted, provided the original author(s) and the copyright owner(s) are credited and that the original publication in this journal is cited, in accordance with accepted academic practice. No use, distribution or reproduction is permitted which does not comply with these terms. 